2021, Volume 16, ATEE 2020 - Winter Conference. Teacher Education for Promoting Well-Being in School. Suceava, 2020, pages: 121-129|

https://doi.org/10.18662/lumproc/atee2020/09

\section{Key Facts about the Decision-making Process of High School Students Regarding Career Options}

\section{Liviu CIUCAN-RUSU ${ }^{1}$ \\ Daniela ŞTEFĂNESCU² Mihai TIMUŞ3}

${ }^{1}$ UMFST „G.E. Palade” of Targu Mures, liviu.ciucan-rusu@,umfst.ro ${ }^{2}$ UMFST „G.E. Palade” of Targu Mures, daniela.stefanescu@umfst.ro

${ }^{3}$ Stefan cel Mare University of Suceava; UMFST „G.E. Palade” of Targu Mures, mihai.timus@u2b.umfst.ro
Abstract: As a dynamic transformation of the economy, companies put pressure on universities and other educational suppliers to deliver the labor force with new knowledge and skills required, to ensure their innovation and competitiveness. Because of these dynamics, students are also under pressure when they must decide about future jobs. There is also confusion in the mind of young adult that needs to bear the influence of public media, social media, online communities about the personal development in regional, national, or global environment. In this case, universities and high schools have to inform about trends and perspectives of future career and support students in their choice but they lack of communication capabilities or marketing aspects are overestimated.

Our study is based on an online survey with more than 500 participants from Mures county high schools during the 2018-2019 academic year. Most of the student wants to continue their study at university $83,2 \%$. As a preferential channel of information about university programs students voted as very useful, university websites and meetings with representatives of faculties. The main fields students interested in are: business, engineering, informatics, medicine, public administration and law. Around 13.4\% of the high school students intend to continue their study abroad. Almost half of the respondents have clear idea of study program to be chosen. Regarding the influence factors of their choice, family and acquaintances who are already university students have the higher impact rather than colleagues, friends and professors. When referring to criteria for choosing the future university, they favor the number of tax-free places and international mobility. Generally, we can say that students consider university the most important next step in their future career and they proof themselves rather independent to decide about this step. Our study also emphasizes significant levels of indecision and we will deepen our further research for better understanding of the phenomenon.

Keywords: career management; decision-making process; academic marketing polices.

How to cite: Ciucan-Rusu, L., Ştefănescu, D., \& Timuş, M. (2021). Key Facts about the Decision-making Process of High School Students Regarding Career Options. In O. Clipa (vol. ed.), Lumen Proceedings: Vol. 16. ATEE 2020 - Winter Conference. Teacher Education for Promoting Well-Being in School. Suceava, 2020 (pp. 121-129). Iasi, Romania: LUMEN Publishing House. https://doi.org/10.18662/lumproc/atee2020/09 


\section{Introduction}

Nowadays economic environment continuously requires new skills and competences of labor force and put more pressure on training and education institutions and on other hand, high school students feel this pressure also. We believe that to solve these problems, state, businesses, and high education institution have to develop a strategy of forecasting future needs of competences based on deep analysis of the environment. To support high school students in their decision-making process, universities and schools have to collaborate and define the key elements which can ensure the deep understanding of future career options of the students(Rose et al., 2019). In other words, they must define what are the most needed and popular career options and what influence the students to choose that options.

In some cases, by choosing the career it means to move from your family and place your growth. In this context, students can be influenced also from financial and material possibilities. Recent studies show that depending on family financial and social status, student can be influenced to migrate from his birthplace in searching for new educational opportunities or to stay in their familiar environment (Rosvall et al., 2018). Moreover, in case of students lacking in social, cultural and economic capital, the school can be the only trustful source of information they can draw on as they consider future career options and identify the university fields of study they need to help them to achieve their ambitions (Haynes et al., 2013). As we now understand, social status and especially the family have very big impact on career option, in some cases students can be restricted to specific job (Meszaros et al., 2009).

Also, the decision of career depends of maturity of students` decidedness, therefore, it is crucial the moment of taking chose, even in any chose of our life. Researchers as (Hirschi \& Lge, 2007) suggest us six-phase model of the career decision-making process:

1. becoming concerned about career decision-making (awareness),

2. generating possible career alternatives based on one's own interests, skills, and values through self- and environmental exploration,

3. reducing the career alternatives to a manageable number for more indepth exploration,

4. deciding among few alternatives,

5. confirming one's choice and building a commitment to it, and

6. being firmly decided and committed to a choice 
The authors also confirmed the important role of school and its curriculum that must boost career choice readiness of the students and support them for career planning based on students` interests and skills. The career choice based on own skills and competences is crucial in nowadays economic environment. Authors as (Bubic, 2014) support our theory by his work which conclude that as much as student is firmly decided about his future career as more satisfaction he will have from future job.

We assume that decision -making process of future career can be influenced by many other factors, besides mentioned above, and some of these factors could be from own behavior and understanding or could be external independent factors. As (Phillips et al., 1985) mentioned, decision making process could be lead by different style of thinking as: rational, intuitive or dependent decision making style.

In specialized literature exist many studies with topics of decisionmaking process of young students and most of them are very important for nowadays environment. To bring value to these research topics, by this study, research team will try to boost the universities implication in supporting young students to choose their future career. In other words, this research paper aims at defining the way how universities could be involved in decision making process of the high school students and what is the role as a key actor.

\section{Research questions/Aims of the research}

This study aims at providing a comprehensive picture of decision making process regarding career options and also, at promoting partnerships and collaboration of universities and high schools to inform high school students about trends and perspectives of future career and support them in their choice. In this way we can ensure that students could enhance the career decision-making maturity. To help universities and high schools to build a sustainable strategy, research team must answer the key questions of this study which are as follows:

1. What are the most preferred career options of high school students?

2. What are the most important criteria for choosing a faculty?

3. What are the main influencers in the decision-making process?

4. What is the degree of certitude of students `career path?

In the following rows we will try to make as clear as possible students`opinions about their career option decision-making process.

\section{Research methods}

\subsection{Participants}


The subjects of the research are $11^{\text {th }}$ and $12^{\text {th }}$ grade high school students from six high schools located in Mures County, Romania. The high schools involved in the research are from different fields of education as: economy, agriculture, math and IT and social science.

\subsection{Materials and instruments}

For collecting data, research team used an online google forms and for data analysis and building visual graphs were used Microsoft Power Business Intelligence application.

\subsection{Procedure}

An online survey was conducted to more than 550 participants from Mures county high schools during the 2018-2019 academic year. During basic analysis process, were validated 511 or $93 \%$ of total responses. The survey was conducted after each university teachers 'presentation in front of high school students from different fields of study. This study represents a basic descriptive analysis of the data collected.

\section{Results}

In the following section we will provide the graphic representation of the key finding of the research and the related comments. These findings will help us to design the final conclusions and recommendation regarding the study. For better understanding of the sample we start with respondents demographic data representation.

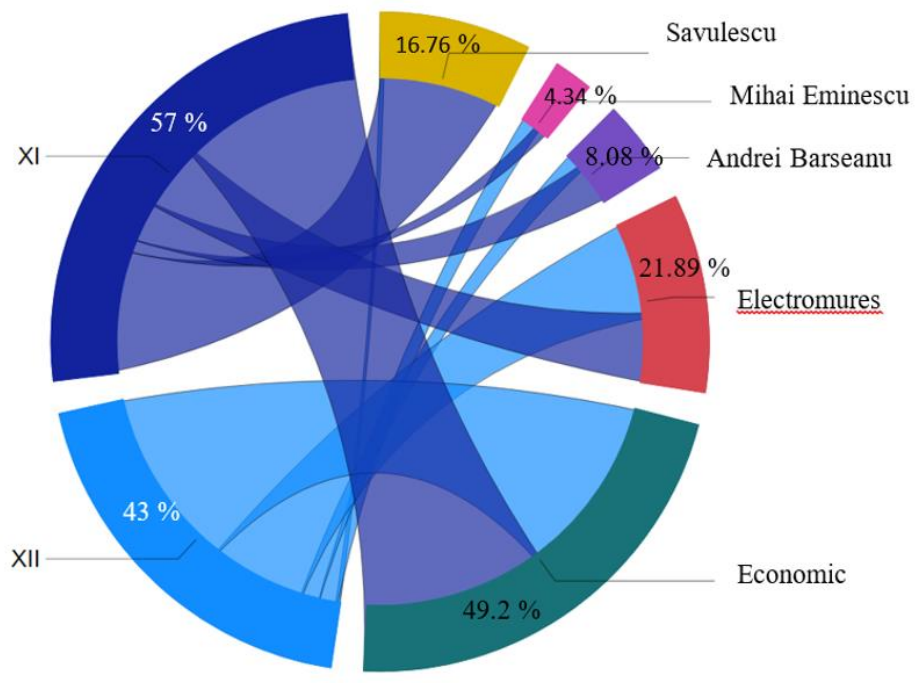

Fig. 1. Distribution of respondents by grade and high school 
Source: Authors own contribution

As we can see in figure 1, the respondents are split between the two final grades in high school, while the majority of receptive respondents' study in the representative institutions from head of Mures County. The distribution reflected in the figure confirms a significant representativity of the sample, taking into consideration the community of high school students.

The next part of our results is dedicated a deeper analysis of variables that influence the decision-making process of high school students regarding career options.

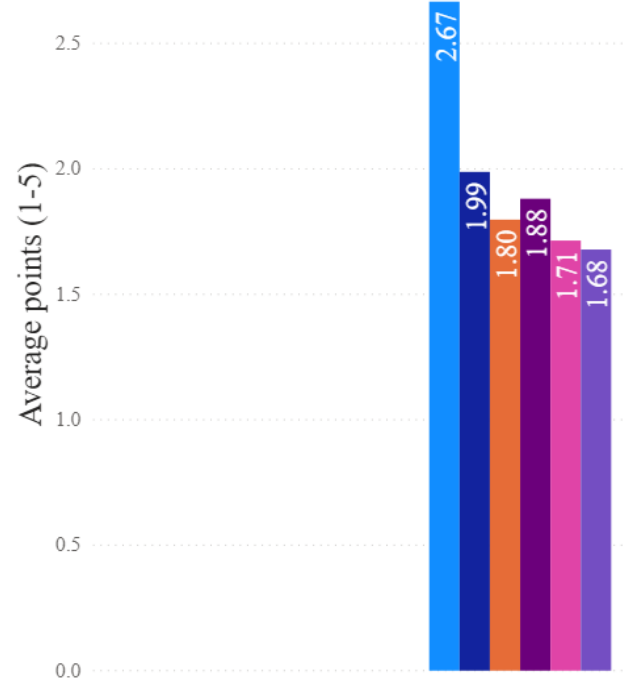

- Family

- Students known

- Specialized teachers

- Friends

- The class teacher

- Classmates

Fig. 2. Factors of influence regarding career options

Source: Authors own contribution

Our findings about the key factors of influencing the decisionmaking process shows that there is a rather balanced distribution, where most of the options were rated less than 2 out of 5 points. We can still emphasize that the family represents the most important influencer, while a peloton of factors doesn't make much difference. Nevertheless, it is interesting to observe that relationships (known students and friends) weight a lot. 


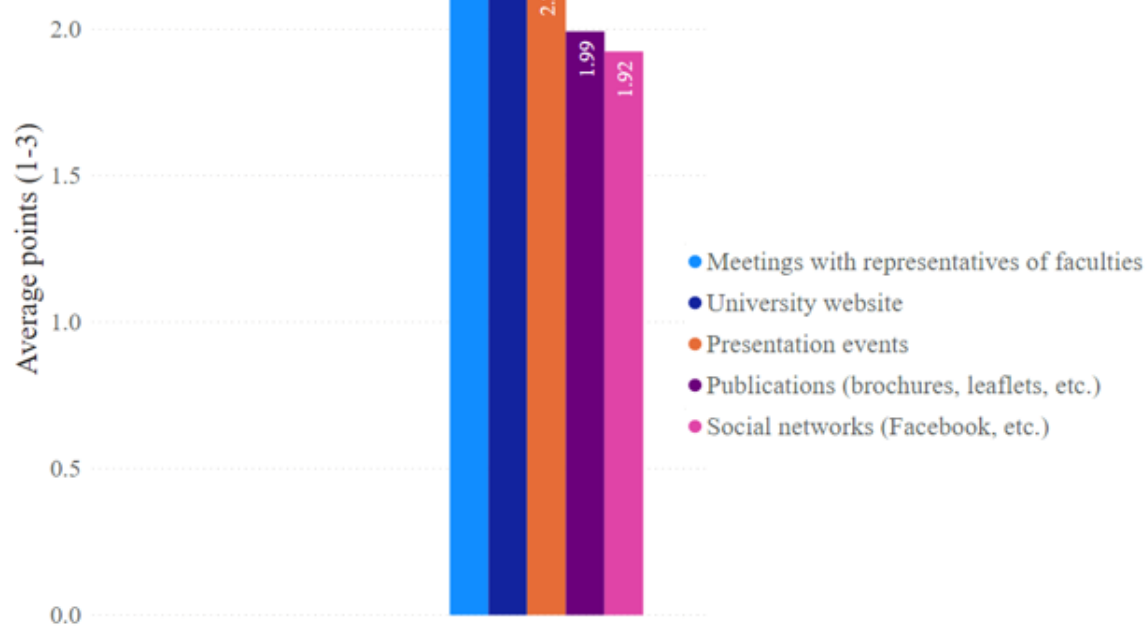

Fig. 3. Academic communication mix options

Source: Authors own contribution

Regarding the academic marketing, we discovered (figure 3) that the most efficient means of communication are as follows: meetings with university representatives, the presentation website of universities and public events. It is still intriguing that social media is an outsider and we assume that its main role is the trigger one.

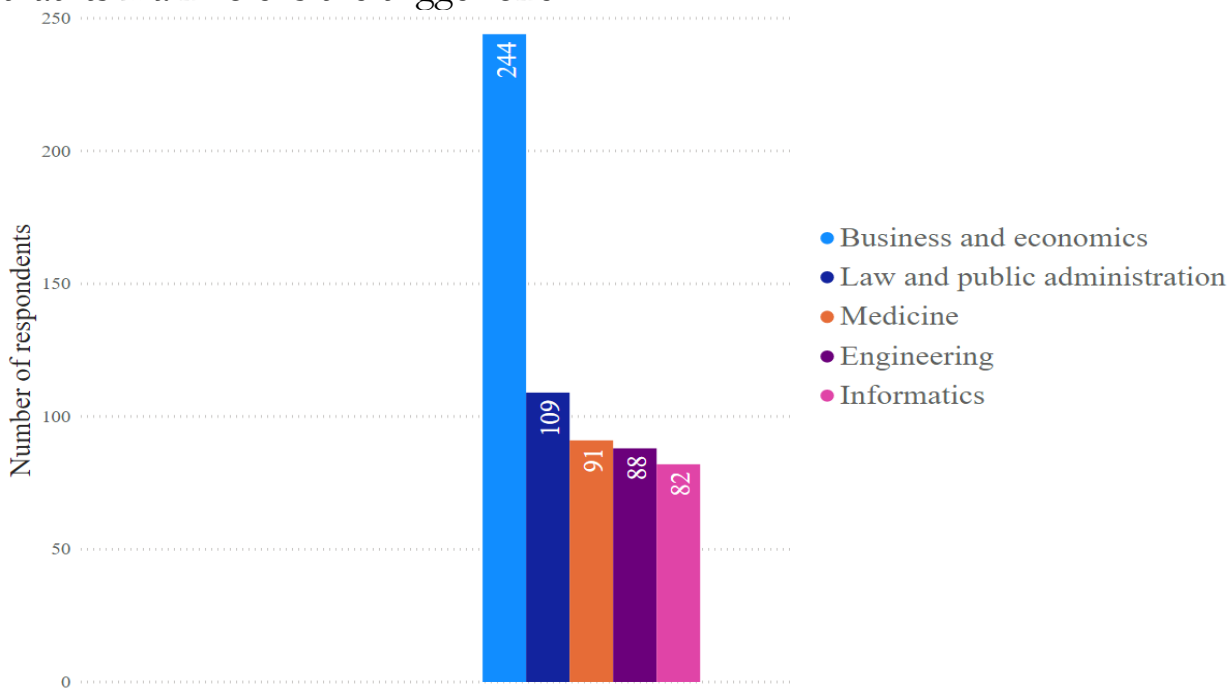

Fig. 4. Preferred future fields of study

Source: Authors own contribution 


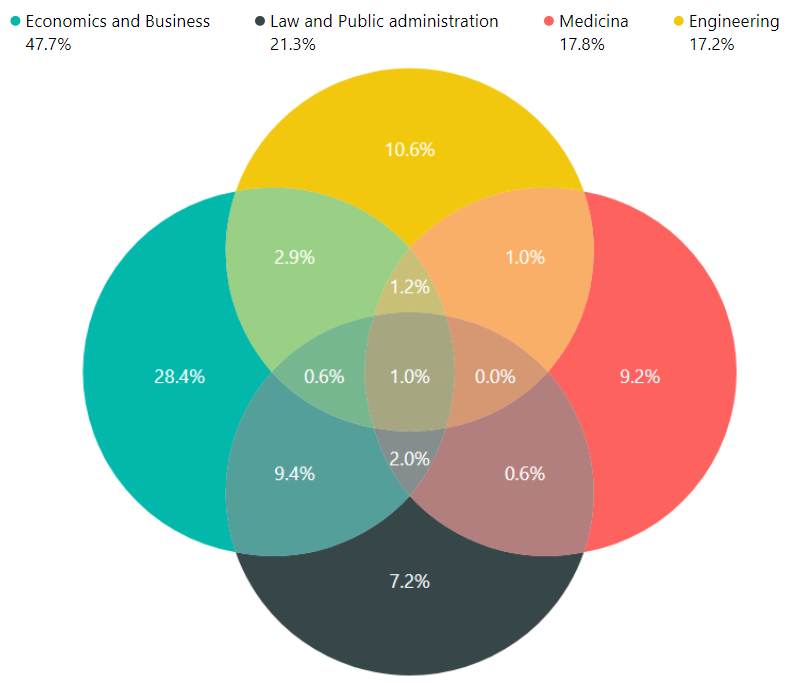

Fig. 5. Preferred mix of future options regarding the field of study

Source: Authors own contribution

Figures 4 and 5 help us to identify the most attractive fields of study. The most popular field of study is business and economics followed by Law and Administration defining a trendy option especially among students in social sciences. The second lot of options (medicine, engineering, and informatics) belong to a rather certain group of respondents, as it is proven in figure 5. Due to the not restrictive multichoice question we identified some interesting combinations, confirming different levels of certainty regarding the chosen fields of study.

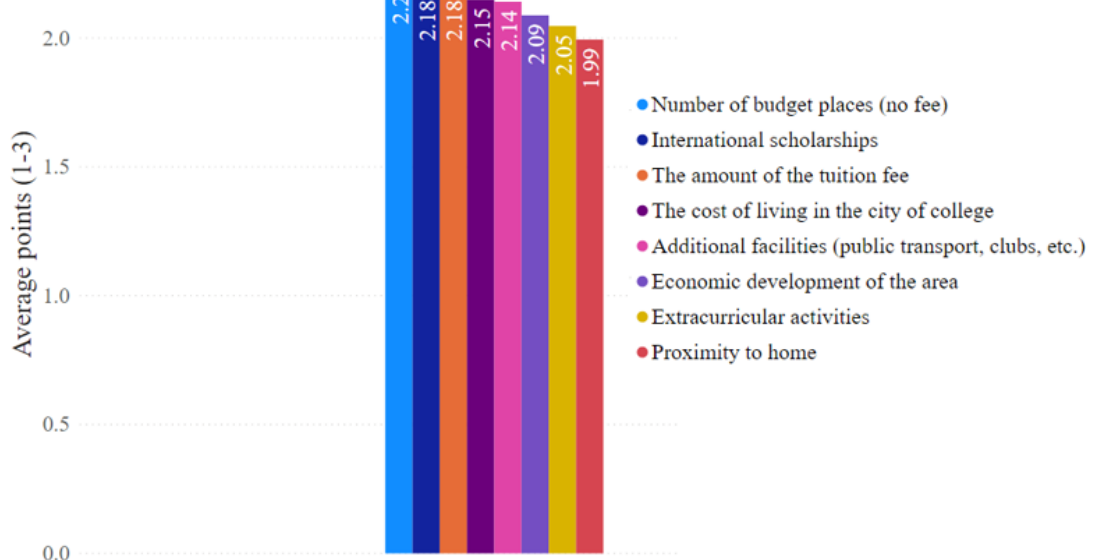

Fig. 6. Preferred criteria for choosing the academic path

Source: Authors own contribution 
Another sensitive topic of our demarche consists of the main criteria for selecting the future university to join. Observing a rather low amplitude of the ratings in figure 6, we can separate two major blocks: the first four criteria bearing financial aspects and the other part driven by living and working environment.

Regarding the decision-making maturity of the respondents we can observe in table 1 that the degree of confidence is not very high, meaning a certain inconsistency about the future specialization that will shape the career.

Table 1. Students` certainty about choosing a specialization (1-5 points)

\begin{tabular}{cccc}
\hline Upper level & Standard Dev. & Lower level & Average \\
\hline 3.651965 & 1.196871 & 3.443925 & 3.547945 \\
\hline
\end{tabular}

Source: Authors own contribution

\section{Discussions}

Our study gravitates around the topic of consumer behavior in the market of educational services. Exploring recent previous scientific work helped us to adopt the subjects and to adapt them in the contest of our regional educational environment. The added value of our demarche resides in the practical implication regarding at list two aspects: a map of students perspective on career path on one hand, and, on the other hand, the marketing approach of universities in Romania, especially in our region. Further research and deeper analysis will grant us the opportunity to find significant functions and relations that can explain the phenomenon associated with career planning decisions.

\section{Conclusions}

In the context of research questions stated, our findings lead us to develop several opinions:

- There are no evident preferences in criteria of choosing a faculty, but the Number of budget places (no fee), International scholarship and amount of tuitions represent top 3 elements.

- Generally, students are still undecided in choosing a faculty even if they rated the confident by 3 or more!

- Economics and business is the most popular field of study in the cluster of this study followed by Law and Public Administration field. 
- The most important influencer in choosing a faculty is Family followed by students known and specialized teachers

We also encourage a closer approach of the phenomenon and an integration of the stakeholders` effort to supply the young students with information and support in their decision-making process regarding career journey.

\section{References}

Bubic, A. (2014). Decision Making Characteristics and Decision Styles Predict Adolescents' Career Choice Satisfaction. Current Psychology, 33(4), 515-531.

Haynes, G., McCrone, T., \& Wade, P. (2013). Young people's decision-making: The importance of high quality school-based careers education, information, advice and guidance. Research Papers in Education, 28(4), 459-482.

Hirschi, A., \& Lge, D. (2007). The relation of secondary students' career-choice readiness to a six-phase model of career decision making. Journal of Career Development, 34(2).

Meszaros, P. S., Creamer, E., \& Lee, S. (2009). Understanding the role of parental support for IT career decision making using the theory of self-authorship. International Journal of Consumer Studies, 33(4), 392-395.

Phillips, S. D., Friedlander, M. L., Pazienza, N. J., \& Kost, P. P. (1985). A Factor Analytic Investigation of Career Decision-Making Styles. Journal of Vocational Behavior, 5, 106-115.

Rose, J., Tikly, L., \& Washbrook, L. (2019). 'Learning to play the game': How schools with below average attainment can support the decision-making processes for high-potential learners in applying for university. British Educational Research Journal, 45(4), 856-872.

Rosvall, P. Å., Rönnlund, M., \& Johansson, M. (2018). Young people's career choices in Swedish rural contexts: Schools' social codes, migration and resources. Journal of Rural Studies, 60(2017 April), 43-51. 